ARTIGO

Recebido em: 09/08/2018

Aceito em: 06/11/2018

\title{
Design da Informação e sua relevância para a Ciência da Informação
}

\author{
Information Design and its relevance to Information Science
}

\author{
João Augusto Dias Barreira e OLIVEIRA (joaodbo@gmail.com)* \\ Maria José Vicentini JORENTE (mjjorente@yahoo.com.br) ${ }^{* *}$ \\ * Doutorando e Mestre em Ciência da Informação pelo Programa de Pós-graduação em Ciência da \\ Informação (PPGCI) da Universidade Estadual Paulista (Unesp) \\ ** Professora do Departamento de Ciência da Informação e do Programa de Pós-graduação em Ciência \\ da Informação (PPGCI) da Universidade Estadual Paulista (Unesp)
}

\begin{abstract}
Resumo
Os avanços sociais, científicos e tecnológicos determinaram transformações nos processos informacionais. 0 problema consiste em compreender a necessidade de apresentar e representar a informação visual, de forma eficaz e eficiente. Busca contribuições do Design da Informação, pouco explorado na Ciência da Informação, e visa determinar um conceito que possibilite o aprofundamento e a atualização científica, acadêmica e profissional em torno da temática, por meio de pesquisa teórica, exploratória, bibliográfica e documental, tendo como base uma revisão de literatura. Os resultados encontrados buscam abrir horizontes para aumentar o interesse da comunidade científica para a temática, promover o debate acerca do Design da Informação e a apresentação eficaz e eficiente de informação para a sociedade. A temática propicia conhecimentos para se atuar proativamente na apresentação visual em ambientes informacionais, podendo resultar em avanços significativos para as disciplinas e os usuários.
\end{abstract}

Palavras-chave: Design da Informação. Ciência da Informação. Apresentação da informação.

\begin{abstract}
The social, scientific and technological advances have determined transformations in the informational processes. The problem is to understand the need to present and represent visual information effectively and efficiently. It looks for contributions of Information Design, little explored in Information Science, and aims to determine a concept that allows the deepening and scientific, academic and professional updating around the thematic, through theoretical, exploratory, bibliographical and documentary research based on a literature review. The results found seek to open horizons to raise interest of the scientific community for the theme, promote the debate about Information Design and the effective and efficient presentation of information for society. The thematic provides knowledge to act proactively in the visual presentation in informational environments, which can result in significant advances for the disciplines and the users.
\end{abstract}

Keywords: Information Design. Information Science. Information presentation.

v. 24, n. $54,2019$. p. $25-37$

ISSN 1518-2924 


\section{INTRODUÇÃo}

As transformações de cunho econômico, social, científico, político e tecnológico impulsionaram o desenvolvimento da humanidade durante cada período histórico. As tecnologias desenvolvidas a partir do início do último século determinaram mudanças que delinearam a sociedade até o momento atual.

O panorama condicionado pela informação disponível na contemporaneidade aponta para uma configuração complexa, expandindo o espectro e alcance das informações de forma rápida e generalizada, refletindo uma clara ruptura com as formas de comunicação do passado. 0 amadurecimento e evolução da infraestrutura da Internet e da World Wide Web possibilitaram novas formas de acesso ao conhecimento, diminuindo barreiras físicas e ampliando à oferta de conteúdo digital ao estabelecer uma rede de compartilhamento de conhecimentos.

O cenário atual aponta para o crescimento constante da quantidade de dados e informações produzidas e disseminadas em âmbito analógico e digital. Há um aumento no número de sujeitos que buscam informações e, por outro lado, uma diversidade de informações disponíveis. Uma série de fatores atua em conjunto compreendendo o acesso, organização, formas de interação, recuperação da informação, até a quantidade e qualidade dos documentos, considerados como suportes que contêm dados e/ ou informações.

Notamos que os avanços tecnológicos, a criação e proliferação de sistemas de informação, a diminuição dos custos em tecnologia e o aumento do processamento e armazenamento de dados e informações em suportes digitais contribuem efetivamente para a disponibilização e disseminação de conteúdos de variados tipos e formatos. Os processos de geração, representação, armazenamento, recuperação, disseminação, uso, gestão, segurança e preservação da informação denotam o papel-chave dos ambientes digitais, espaços institucionais ou não, que disponibilizam documentos diversos em formato digital. Bibliotecas, arquivos e museus resguardam informação, memória e patrimônio de forma interligada e passam a existir em meio digital, conservando, disseminando e preservando o conhecimento.

A expansão, importância e influência dos sistemas de informação, demandam novos olhares acadêmicos, visto que, estes ambientes atuam como suporte do conteúdo informacional textual e imagético apresentados aos sujeitos, participantes ativos do processo comunicacional. Em meio à explosão de dados é necessário, por meio de uma abordagem interdisciplinar, desenvolver conhecimentos que visem contribuir para a solução dos problemas de design e de apresentação da grande quantidade de informações presentes em ambientes digitais.

Considerando a nova configuração social em relação à informação, buscamos contribuições inter e transdisciplinares entre duas áreas do conhecimento que atuam diretamente com a informação, a Ciência da Informação e o Design da Informação. A aproximação com outra área do saber, que lida com a linguagem visual, procura investigar e resolver problemas que ainda carecem de solução e se faz pertinente, tendo em vista a ampliação e a socialização do conhecimento no âmbito da Ciência da Informação.

Entre as inúmeras definições e traduções do termo Design, utilizamos uma combinação que contempla aspectos de projetar, desenhar, esboçar, designar, planejar, delinear em termos de projetos, planos, desenhos, esquemas, modelos, etc., pois o conceito está relacionado e abrange, ao mesmo tempo, estas nomenclaturas. Possibilitando o aprofundamento e a atualização científica, acadêmica e profissional em torno da temática na área da Ciência da Informação.

0 artigo tem por objetivo preencher uma lacuna conceitual existente, propondo subsídios teóricos, visando apoiar soluções eficazes para as questões que envolvem a representação e apresentação de informação visual. Buscamos definir a disciplina "Design da Informação" para assim determinar um conceito de referência sobre a temática direcionada à apresentação da informação visual.

0 problema consiste em compreender a necessidade de apresentar e representar, de forma eficaz, a informação visual. Diante disso, o levantamento que procuramos realizar a respeito do Design da Informação é necessário, visto que a temática é pouco explorada na Ciência da Informação e atua diretamente sobre o problema em representar informação de forma eficaz e eficiente. 


\section{EXPERIÊNCIA DO USUÁRIO NA WEB NO CONTEXTO DA CIÊNCIA DA INFORMAÇÃO}

A configuração do paradigma emergente que circunda a Ciência da Informação em seu atual momento e passa a vigorar na pós-modernidade, de cunho pós-custodial, informacional e científico possui como traços principais a valorização da informação enquanto fenômeno humano e social, sendo a materialização num suporte um epifenômeno (ou derivado informacional); constatação do incessante e natural dinamismo informacional oposto ao "imobilismo" documental; prioridade máxima concedida ao acesso à informação por todos, mediante condições específicas e totalmente definidas e transparentes; imperativo de indagar, compreender e explicitar a informação social, por meio de modelos teórico-científicos cada vez mais exigentes e eficazes, em vez do universo rudimentar e fechado da prática empírica (SILVA; RIBEIRO, 2011).

A Ciência da Informação, como ciência social, também conduz seus estudos para os sistemas e as articulações envolvidas nessas interações dos contextos sociais em que estão inseridos; fato percebido recentemente na busca da afirmação de novos paradigmas epistemológicos. "Paradigmas que levem em conta as novas formas de codificação, decodificação, atualização e absorção da informação tramitada digitalmente, no presente caso imagéticas e intersemióticas." (JORENTE, 2009, p. 224).

Por tratarmos de um campo que busca investigar um variado espectro de condições informacionais, a problemática inerente a outras áreas do conhecimento refletirá sobre a Ciência da Informação, evidenciando certas características que nortearão seu escopo epistemológico, sua área de atuação e as questões a que se propõe a investigar. A questão social é prioritária nas ciências sociais aplicadas. Ampliar os horizontes de pesquisa, frente à configuração do fenômeno informacional atual, se faz necessário. A interdisciplinaridade passa a se tornar uma das principais características da Ciência da Informação, integrando conceitos de forma mútua.

0 uso de tecnologias tem promovido a otimização da disseminação da informação nos ambientes digitais, como em bibliotecas, arquivos, museus, repositórios, websites e outros. De acordo com Macedo (2005, p. 136), "ambiente informacional é um espaço que integra contexto, conteúdo e os usuários".

A base teórica utilizada na pesquisa para definir o conceito de experiência do usuário na Web consiste em um modelo teórico já estabelecido, com aplicação prática efetiva, sendo utilizado até mesmo fora da Web. Publicado por Garrett (2002) o livro "Elements of User Experience" aproxima o leitor das disciplinas que atuam na $W e b$, representado por um modelo apresentado na Figura 1.

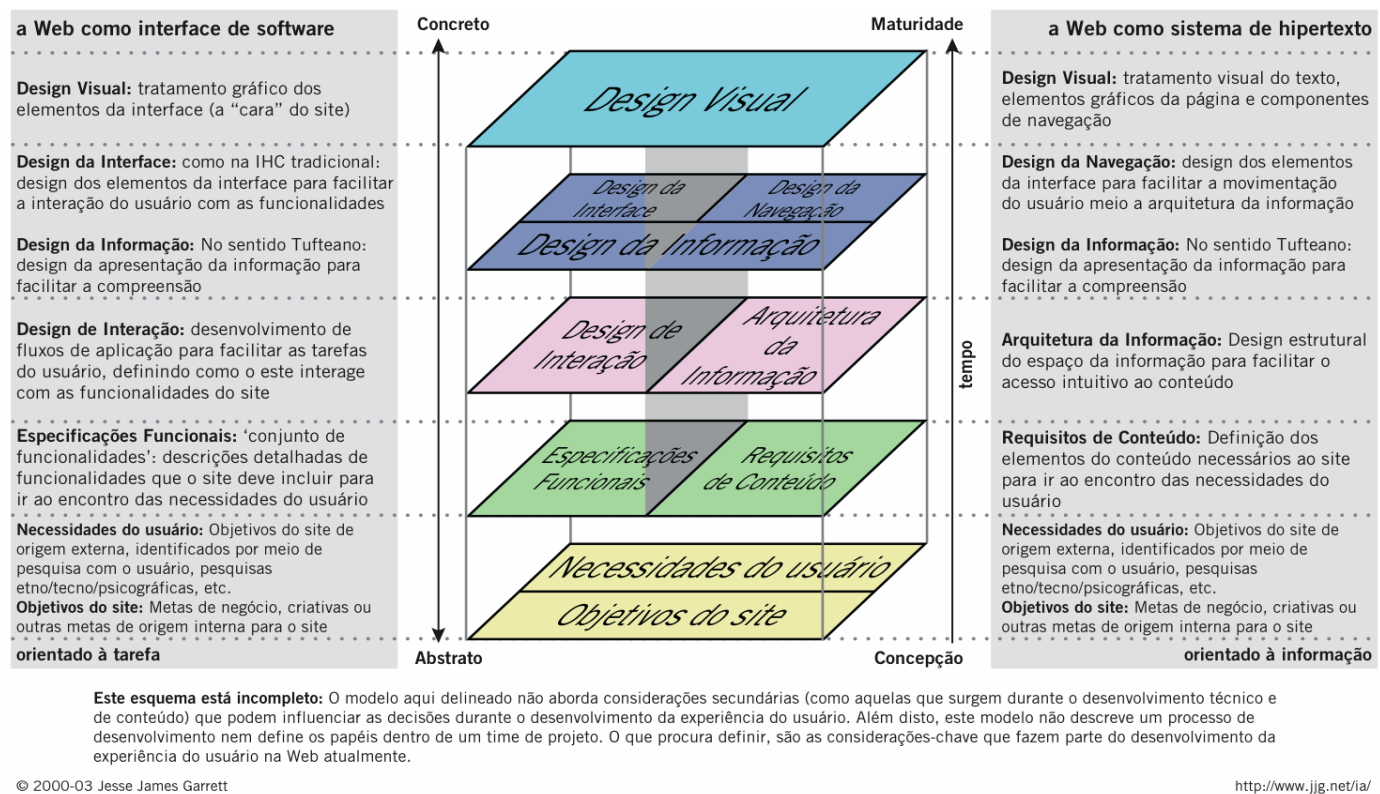

Figura 1: Modelo dos elementos da Experiência do usuário.

Fonte: GARRETT (2002). 
0 autor define os elementos dividindo-os em cinco planos distintos, da parte inferior da figura até o topo, parte-se de conceitos abstratos para concretos. A definição dos planos está a seguir:

a) Plano Estratégico, localizado na base da Figura 1, corresponde as necessidades do usuário e objetivos do website (ou página na Web);

b) Plano Escopo, acima do plano estratégico, contém os requisitos de conteúdo e especificações funcionais;

c) Plano Estrutura engloba a Arquitetura da Informação e o Design de Interação;

d) Plano Esqueleto corresponde aos elementos Design de Informação, Design de Interface e Design de Navegação;

e) Plano Superfície, no topo da Figura 1, abrange o Design Visual ou Design Sensorial.

Garret (2002) deixa claro que este modelo não descreve um processo de desenvolvimento a ser seguido, servindo como base para relacionar disciplinas que atuam na interação entre homem e sistema. Busca definir considerações que pautam o desenvolvimento da experiência do usuário dentro e fora da Web sendo assim, utilizamos em nossa análise as disciplinas de caráter mais concreto do modelo de Garret (2002), que englobam as camadas estrutura, esqueleto e superfície.

Na camada de estrutura, a disciplina de Arquitetura de Informação visa criar formas de se estruturar a informação em um ambiente informacional ao organizá-lo por meio de métricas e metodologias e entregáveis dessa disciplina. 0 Design de Interação é o responsável por aferir e oferecer soluções visando à capacidade e potencialidade das interações resultantes de um processo comunicacional de informação homem-máquina. Nesse caso trata sobre as melhores práticas a serem conduzidas nesse aspecto em relação a um ambiente informacional na $W e b$, ou seja, como a interação com a informação pode ser facilitada e distribuída de forma mais rica, conduzindo a uma experiência do usuário que seja frutífera.

A camada esqueleto é formada por três disciplinas. 0 Design de Informação atuará no sentido de facilitar a comunicação por meio da apresentação precisa da informação. Busca definir métodos e práticas que atuem com o objetivo de tornar clara uma mensagem, otimizando a aquisição de informação pelo usuário e facilitando o processo de apreensão da informação para a tomada de decisão. A sinalização de ambientes, de caráter físico ou digital, é um dos processos desenvolvidos por esta disciplina, atuando para facilitar a localização do usuário seja em um ambiente físico ou em um sistema digital. 0 Design de Interfaces visa analisar e aperfeiçoar a interface do sistema, propondo melhorias na maneira com que as informações estão dispostas e organizadas e como esta interface irá interagir com o usuário. Engloba a criação de menus, ícones e itens necessários para a devida interação do usuário com o sistema. 0 Design de Navegação trata sobre os caminhos e percursos do ambiente na Web, atuando como facilitador ao acesso à informação, destacando as condições existentes para o usuário navegar entre as páginas. (GARRETT, 2002).

A camada superfície compreende o Design Visual, entendido também como Design Sensorial. Nesse caso a tradução para o português corresponde à disciplina de Design Gráfico ou Desenho Industrial em algumas instituições. As duas formas de tratar a camada com termos diferentes, mas que significam o mesmo, acontece devido à concentração dessa camada no topo do modelo. Primeiramente entendida como Visual, tal camada não se resume a apenas isso, podendo atuar em diferentes sentidos no que tange uma experiência abrangente. Foca-se primeiramente no visual, para assim propor considerações acerca do processamento de informações sensoriais do ser humano. Tal enfoque busca uma contemplação abrangente acerca de garantir uma experiência visual e sensorial satisfatória. Lembramos que tal modelo por ser estendido para ambientes físicos, como em exposições museológicas que podem enriquecer a experiência do usuário ao fazer uso de outros sentidos como a audição, olfato e o tato. (GARRETT, 2002).

Os elementos atuando em suas especialidades, como funcionalidades e conteúdo informacional, busca atender as necessidades dos usuários que deverá ser pesquisado, entrevistado, realizar testes e oferecer feedback acerca do desempenho de sua atividade em um sistema web por exemplo. As avaliações do usuário (acessibilidade, usabilidade, navegabilidade, entre outras) são de extrema relevância para identificar possíveis problemas 
e forma de aprimorar a interação com o sistema, compreensão das informações visuais e a experiência na plataforma como um todo. Como um ciclo, as camadas do modelo da Figura 1 se complementam e se relacionam. Por meio do resultado de avaliações com os usuários é possível realizar alterações em cada disciplina como forma de obter uma experiência na web eficaz, eficiente e satisfatória.

$\mathrm{Na}$ Web podemos citar diversos ambientes com características próprias como os blogs, fóruns, as wikis colaborativas, redes sociais, websites de compartilhamento de mídia audiovisual que fomentam os agentes dos processos comunicacionais a agregar conteúdo informacional de forma livre. A computação ubíqua atua como um eixo que propulsiona a oferta e demanda por aplicativos, softwares, ferramentas e websites tornando a associação entre informação e computação inexorável. A mobilidade proporcionada pelos dispositivos de comunicação transforma dinamicamente o panorama informacional atual.

Entre as competências técnicas necessárias identificamos alguns pontos focais que norteiam a atividade profissional em consonância com a demanda por informação especializada dos sujeitos informacionais do mundo atual. Na área de Ciência da Informação, o conceito de Blended Librarian (bibliotecário híbrido) cunhado por Steven Bell e John Shank em 2004, é um exemplo na atualização interdisciplinar do bibliotecário, posicionando o profissional da informação como agente proativo no processo infocomunicacional, amparado em sua competência instrucional. Segundo os autores, esse profissional é um bibliotecário que atua em bibliotecas universitárias e que combina o conjunto tradicional de habilidades biblioteconômicas "[...] com as habilidades em hardware e software dos profissionais de tecnologia da informação e a capacidade do designer instrucional ou educacional visando aplicar a tecnologia de forma apropriada no processo de ensino-aprendizagem" (BELL; SHANK, 2004, p. 373, tradução nossa).

Compreender o paradigma emergente com foco no profissional da informação é importante, pois sua atuação diante das transformações sociais necessita de atualização constante. Isto não significa afastá-lo de suas atribuições primordiais, mas reposicionar sua atuação para os principais focos de atenção, como a informação disponível em meio digital.

\section{METODOLOGIA}

Este estudo buscou utilizar uma metodologia capaz de compreender de forma abrangente e holística o objeto de estudo em evidência. Situamos o universo teórico e prático das disciplinas Ciência da Informação e Design da Informação por meio de uma abordagem sistêmica. Visamos conceituar a disciplina Design da Informação no âmbito da Ciência da Informação com base na revisão da literatura do tema.

A delimitação da pesquisa residiu inicialmente em conceituar o termo e a disciplina, pois a produção em Ciência da Informação sobre a temática é insuficiente e não contempla tais características. A abordagem sistêmica permitiu uma representação dinâmica da realidade por meio da visualização de interconexões implícitas e explícitas de elementos internos e externos às disciplinas.

Estabelecemos a forma de pesquisa bibliográfica, como ponto principal de apoio para a coleta de dados por meio do estudo teórico, exploratório, bibliográfico e documental. Buscamos propiciar uma perspectiva de análise inicial ao explorar e compreender os conceitos fundamentados em outra área do saber para verificar sua importância frente à Ciência da Informação com base em uma revisão de literatura. Dessa forma poderemos indicar novas perspectivas em pesquisas e potencialidades.

Em um levantamento realizado nas bases de dados multidisciplinares Web of Science e Scopus, que indexam o conteúdo dos principais periódicos mundiais, com o intuito de identificar a produção de artigos científicos sobre Design da Informação para se ter uma visão geral quantitativa do que já foi publicado e investigar na literatura de Ciência da Informação a ocorrência de artigos que tratam de uma inter-relação entre as disciplinas.

Para a expressão de busca "Information Design" nos campos título, assunto e palavras-chave na plataforma Web of Science encontramos 668 publicações, com 319 artigos. Ao restringir artigos da área de Ciências Humanas temos um total de 126. Na base de dados Scopus a mesma busca resultou em um total de 1.600 publicações, com um total de 863 
artigos. Na área de Ciências Humanas são 365 artigos no total. Nesse total há periódicos que são indexados pelas duas bases de dados. A distribuição temporal das publicações pode ser visualizada no gráfico 1 e corresponde as publicações na Web of Science do lado esquerdo e na base Scopus ao lado direito.

Gráfico 1: Publicações de artigos sobre design da informação nos últimos anos nas bases Web of Science e Scopus.

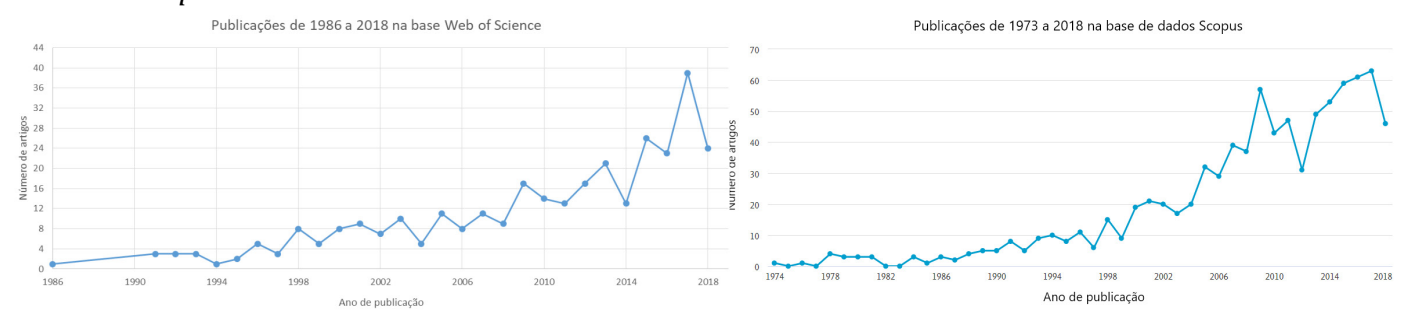

Fonte: Dados da peesquisa, 2018.

0 Design da Informação, área com início recente, apresentou crescimento de publicações a partir de 1979, principalmente com a fundação do Information Design Journal, periódico em funcionamento até hoje que proporcionou um ambiente para comunicação científica mais acessível para os designers. Este periódico publica artigos e comunicações de pesquisas e está indexado apenas na Scopus, o que resulta em um maior número de publicações recuperadas nessa base. Um outro fato recente consiste na publicação em novembro e dezembro de 2017, do volume 6, número 6, do periódico El professional de la informacion da área de Ciência da Informação, cujo tema era Design da Informação, contendo 9 artigos, em sua maioria de pesquisadores espanhóis.

Na etapa de levantamento bibliográfico, de 1970 até 2010, recuperamos três artigos em língua inglesa, que exploram uma aproximação das disciplinas de Ciência da Informação e Design da Informação. Estes artigos foram publicados em 1991, 2000 e 2007 respectivamente e tratam o tema em contextos específicos. É possível notar um lapso significante de tempo entre as publicações tendo em vista as transformações científicas e tecnológicas decorrentes nesse período.

Orna e Stevens (1991), no artigo "Information design and information science: a new alliance?", são os primeiros a publicar uma possível aproximação das disciplinas com enfoque na prática dos profissionais da informação. A experiência dos autores no ensino permitiu vislumbrar que é possível conscientizar pessoas sem treinamento em design, sobre as principais características do Design da Informação. Trabalhos desenvolvidos com profissionais da informação sugerem que é possível ensinar design ao ponto em que estes possuam conhecimento suficiente e uma competência útil para resolver problemas de design em seu ambiente e trabalhar produtivamente com designers. Entretanto, não foi possível recuperar os trabalhos citados em que este experimento ocorreu.

Tramullas (2000), em "Planteamiento y componentes de la disciplina Information Design", visa utilizar fundamentos do Design da Informação no contexto da documentação no panorama Web e do documento digital dinâmico potencializando a comunicação da informação. Orna (2007) retoma a discussão com o texto "Collaboration between library and information science and information design disciplines. On what? Why? Potential benefits?" com foco em produtos informacionais no contexto de gestão da informação em empresas e seus ambientes digitais por meio da união entre profissionais da informação, designers de informação e profissionais de tecnologias de informação e comunicação.

Acreditamos, entretanto, que a forma como o tema é tratado por esses autores considera apenas o aspecto prático de atuação dos profissionais envolvidos, deixando de fundamentar a possível apropriação teórica relacionada à temática ou de expandir suas reflexões para outras vertentes da área de Ciência da Informação. Nos últimos anos o panorama vem se alterando, com um maior número de publicações sobre design da informação na área de Ciência da Informação.

Por tratar-se de um estudo sobre o Design da Informação no contexto da Ciência da Informação, o caráter de ineditismo da pesquisa é auxiliar na construção de conhecimento que se torna, a cada dia, fundamental para a disciplina de Ciência da Informação 
considerando a apresentação de informação em ambientes informacionais digitais ou analógicos.

\section{DESIGN DA INFORMAÇÃO E CONCEITOS}

Essa seção apresenta, de forma sucinta, contribuições que visam determinar o contexto do objeto de estudo, primeiramente tratando da relação com a área do Design gráfico, para melhor compreender as dimensões da disciplina Design da Informação, como os processos, atividades e aplicações práticas.

Para melhor situar o leitor é necessário compreender a disciplina Design da Informação como uma subárea do Design gráfico, responsável pela programação e apresentação visual. A primeira função do Design gráfico, a principal, é identificar, dizer o que é determinada coisa, ou de onde ela veio (letreiros de lojas, estandartes e brasões, símbolos de editores e gráficas, logotipos e marcas de empresas, rótulos em embalagens e outros). Sua segunda função, conhecida no âmbito profissional como Design da Informação, é informar e instruir, indicando a relação de uma coisa com outra quanto à direção, posição e escala (mapas, diagramas, sinais de direção). A terceira função, muito diferente das outras duas, é apresentar e promover (pôsteres, anúncios publicitários); aqui, o objetivo do design é prender a atenção e tornar sua mensagem inesquecível (HOLLIS, 2000).

Nesse sentido, o Design da Informação amplia-se e resulta em uma área do conhecimento, disciplina científica e atividade. Rubin (1988, p. 12) aponta a preocupação com o usuário da informação ao delimitar que "todo o design para utilização do público deve ser baseado em algum conhecimento dos usuários e da(s) tarefa(s) que estes irão realizar com o objeto projetado".

Pontis (2012) aponta que a origem do Design da Informação coincide com as primeiras inscrições em cavernas, ou seja, são estas as primeiras tentativas do homem de comunicar informação de forma eficaz e eficiente por meio da apresentação do conteúdo visual. Por meio da cronologia da área verificamos que a disciplina surgiu e se desenvolveu obtendo contribuições importantes das Ciências Exatas, Humanas e Biológicas. A busca por representar e apresentar a informação de forma eficaz e os resultados atingidos em outras áreas do conhecimento refletiu na função do Design da Informação. Entre as suas várias definições, temos:

Design da informação é definido como arte e ciência de preparar informação para que possa ser utilizada por seres humanos com eficiência e eficácia. Design da informação significa comunicação por palavras, imagens, tabelas, gráficos, mapas e desenhos, por meios convencionais ou digitais. (JACOBSON, 1999, p. 84, tradução nossa).

Assim, esta área busca aprimorar a capacidade dos usuários em coletar, processar e disseminar informação e de produzir o entendimento da mensagem. Outra consideração importante reflete sobre a ciência e os objetivos da disciplina implicando em suas aplicações práticas:

Definido como a ciência de preparar as informações para que elas possam ser usadas por pessoas com eficiência e eficácia. Possui como objetivos principais:

1. Desenvolver documentos que sejam compreensíveis, precisos e rapidamente recuperáveis, além da sua transformação fácil em ações efetivas;

2. Projetar interações por meio de equipamentos que sejam naturais, fáceis e agradáveis. Isto envolve resolver os problemas do design da interface humano-computador.

3. Permitir que as pessoas se orientem em um espaço tridimensional com facilidade e conforto, sendo esse espaço principalmente o espaço urbano, mas também o espaço virtual (HORN, 1999, p. 15, tradução nossa).

Ressalta-se a caracterização dada por este autor aos processos de recuperação de informação, agregando o fator de interatividade à definição e obtendo uma estreita relação com o design de interfaces e de interações. 0 designer de informações pode oferecer 
soluções por meio de instrumentos, ferramentas, produtos ou mensagens criadas para diferentes mídias, como a impressa, na $W e b$ ou em outro ambiente da Internet. Essa organização pode acontecer de inúmeras formas envolvendo a apresentação de conteúdos hipertextuais compreendendo texto, imagens, áudio e vídeo.

0 Design da Informação, enquanto disciplina, tem como função primordial a "comunicação eficiente da informação, e isto implica a responsabilidade de que o conteúdo seja correto e objetivo em sua apresentação" (WILDBUR; BURKE, 1998, p. 6). Independentemente do suporte informacional utilizado, um projeto gráfico adequado busca satisfazer de forma estética, econômica e ergonômica o sujeito que interagirá com a informação, por meio da mensagem. Um dos elementos presentes na disciplina Design da Informação corresponde a infografia. Termo utilizado para descrever representações visuais complexas, de modo que comunicá-las apenas textualmente, dificultaria o entendimento. Contextualizamos o termo infografia, segundo Meirelles (2013, p. 11, tradução nossa).

\begin{abstract}
A comunidade do design gráfico usa principalmente dois termos para a apresentação de informação visual: infografia e design da informação. Em poucas palavras, infografia significa apresentações visuais em que gráficos (ilustrações, símbolos, mapas, diagramas, etc.) juntamente com a linguagem verbal comunicam informação que não seria possível de outra forma. Infográficos podem variar desde as primeiras ilustrações científicas do corpo humano às representações modernas da forma como o cérebro funciona, dos primeiros mapas de rotas e horários de trem para o emblemático mapa do metrô de Londres, o jornalismo, bem como livros técnicos e pedagógicos, empregam práticas estabelecidas que tradicionalmente têm utilizado infográficos para explicar informações complexas e contar histórias. A partir do familiar mapa do tempo até explicações visuais dos fenômenos naturais e fatos recentes, infográficos nos ajudam a melhor entender as notícias em nosso redor.
\end{abstract}

Dessa forma, os infográficos respondem por efetivar o processo de comunicar informações de forma precisa e eficiente ao agregar um conjunto de dados relevantes na forma de gráficos, diagramas, mapas, materiais de sinalização e outros, ao conteúdo informacional que pretende apresentar, utilizando-se de técnicas de representação moldadas para melhor informar, de maneira que os usuários entendam e utilizem o conhecimento de forma significativa. Este é um dos principais desafios da área frente à crescente demanda e oferta de informação digital e o surgimento de dispositivos móveis como celulares e tablets que possuem características próprias de disponibilização e apresentação de informação. da disciplina.

Meirelles (2013) complementa a definição de alguns possíveis resultados e objetivos

\begin{abstract}
Por outro lado design da informação é amplamente utilizado para descrever práticas de comunicação em que o principal propósito é informar, em contraste com abordagens persuasivas mais comumente aplicadas em práticas como publicidade. Infografia é um dos possíveis resultados dentro da grande disciplina de Design da Informação. Outros resultados possíveis envolvem a concepção de sistemas, que podem ser exemplificados pelos sistemas de informação, sistemas de wayfinding (sinalização) e visualizações de dados estatísticos. Todos os exemplos compartilham o objetivo comum de revelar padrões e relacionamentos desconhecidos ou não tão facilmente deduzidos sem o auxílio da representação visual de informação. (MEIRELLES, 2013, p. 11, tradução nossa).
\end{abstract}

O objetivo da disciplina é de especificar representações de objetos e ações de uma tarefa, que irão ajudar os que estão interagindo com os produtos de um projeto de design, a perceber, interpretar e dar sentido ao que está acontecendo. Estes sujeitos devem "ser capazes de determinar o status da sua atividade corrente e o que eles podem fazer para atingir seus objetivos. " (CARROLL; ROSSON, 2002, p. 162). O objetivo é assegurar a efetividade da comunicação, a partir da facilitação de processos de percepção, leitura, compreensão, memorização e uso da informação apresentada (FRASCARA, 2011).

Sua colaboração se dará por meios diversos, que contribuirão para a seleção, arranjo, hierarquização e combinação de distinções visuais, visando à facilitação de “[...] 
ações efetivas, o design da informação abre novas possibilidades para os usuários, e sendo consistente facilita o aprendizado de uso da interface e de seu conteúdo. " (BONSIEPE, 1997, p. 12).

O Design da Informação é, antes de tudo, uma disciplina orientada para o usuário. Em uma perspectiva atual e dinâmica, proveniente da Ciência da Informação reúne os principais aspectos epistemológicos da disciplina.

Se contemporaneamente a informação é um bem valioso, o Design da Informação (DI) trata de estudar a percepção e cognição humana para definir e criar modelos visando à melhoria dos trânsitos de conteúdos informacionais em diversos meios e contextos; trata, por outro lado, da representação da informação, de suas estruturas e codificação. Ao atuar nas formas de recepção e de produção de informação, cria meios para facilitar o processo de aquisição da informação e do conhecimento, que se efetivam a partir dos sistemas de comunicação, sejam estes analógicos ou digitais.

O Design da Informação é multidimensional, pois, ao equacionar aspectos sintáticos, semânticos e pragmáticos da miríade dos sistemas de informação que se integram cotidianamente na comunicação humana, define o planejamento e a produção de discursos informacionais convergidos desde sempre nos processos comunicacionais; para tal fornece ferramentas, estratégias de criação e interação de interfaces para a comunicação, o acesso, a usabilidade e a acessibilidade. (JORENTE, 2015, p. 11)

Para satisfazer às necessidades informacionais dos indivíduos que irão interagir com a informação, a atividade de design da informação compreende análise, planejamento, apresentação e o entendimento de uma mensagem, levando em conta seu conteúdo, linguagem e forma que é apresentada (PETTERSSON, 2002). Em um sentido mais amplo, consiste na seleção, organização e apresentação da informação para um público determinado. Na visão de Tufte (1983), com um design refinado pode-se elegantemente revelar complexidade. Alguns de seus exemplos de visualização de dados estatísticos permitem compreender que a apresentação de determinados tipos de informação podem acontecer de diferentes formas, favorecendo a apreensão de informação dos receptores.

A atividade de design da informação ocorre em ambientes informacionais analógicos e digitais, que buscam apresentar de forma visual certos pontos, como seus objetivos, levando em conta seu público-alvo, processos e resultados buscados. A organização de dados e informações é um processo que procura reconhecer o sentido do conteúdo para refinar e reduzir uma abundância de dados em informação significativa e passível de utilização.

Por meio de representações, o design da informação possibilita apresentar visualmente variáveis que não poderiam ser vistas e comparadas naturalmente. Katz (2012) demonstra essa função ao criar um infográfico comparando o tamanho relativo dos planetas utilizando frutas como medida proporcional. Da mesma forma é possível desenvolver a criação de materiais de instrução utilizando técnicas para a diagramação do texto, juntamente com as ilustrações precisas de cada conceito, auxiliando o leitor em compreender as instruções de forma conjunta. Esse processo também potencializa a visualização de variáveis que podem ser vistas na realidade.

Em outra dimensão prática da disciplina alia-se funcionalidade com a forma e tipo do material (suporte) informacional. Como exemplo, o design de um objeto capaz de informar o usuário; a bandagem Vernaid (COOPER HEWITT MUSEUM, 2018) contêm diversas instruções textuais e imagéticas com possibilidades de uso da bandagem impressas no tecido, integrando o manual de utilização ao objeto. Assim, a função do design da informação não é somente estética como alguns acreditam, mas esta lida com a necessidade de solucionar problemas como evidenciar, revelar e comunicar visualmente os relacionamentos existentes na complexidade dos sistemas.

Apresentamos, a seguir, de forma sucinta, alguns ambientes informacionais digitais que possuem em sua estrutura e conteúdo, aspectos ligados à prática do Design da Informação. Tais ambientes se relacionam com área da Ciência da Informação e contribuem para explorar aspectos importantes ao lidar com formas de apresentação da informação. 
Jorente (2011), ao analisar o website National Archives Experience Digital Vaults, indica o impacto de tais ambientes híbridos no contexto das Instituições arquivísticas. Esse ambiente informacional digital agrega os instrumentos de pesquisa tradicionais de Arquivos, funcionando como um guia, inventário e catálogo interativo da coleção por meio da exploração de forma lúdica e intuitiva. A organização é dinâmica e segue uma lógica que interliga documentos em um design de visualização dos itens documentais de princípio interativo. Este espaço oferece novos aspectos estéticos, mas principalmente visa ampliar a cognição dos indivíduos ao oferecer uma inovação em relação a outros websites tradicionais de Arquivos Públicos e está inserido no paradigma pós-custodial da Ciência da Informação.

De modo similar, a interface da Biblioteca do Congresso americano (LIBRARY OF CONGRESS, 2018) utiliza recursos imagéticos e audiovisuais integrados em seu design. A diagramação desse ambiente informacional responde pelo uso de variáveis gráficas e tipográficas combinando informação visual textual e imagética de forma equilibrada. Não há distrações em meio às informações dispostas visualmente, sendo assim sua apresentação é objetiva, de forma clara e concisa, adequada ao tipo de arquitetura de informação utilizada. Em ambientes informacionais museológicos destacamos a objetividade e clareza da Tate Gallery (TATE MUSEUM, 2018) do Reino Unido, por ofertar diversos recursos informacionais como galerias de imagens, exibições virtuais online, vídeos educativos, aplicativos para smartphones, textos e arquivos sonoros. Enriquecendo a experiência do usuário ao evidenciar as principais características do contexto de cada exposição.

Por meio dos exemplos de ambientes digitais, traçamos um panorama das aplicações de design da informação atuais. Existem, além destes, inúmeros exemplos de websites de instituições que favorecem o processo de comunicação da informação por meio da efetiva apresentação do conteúdo. Destacamos que os conteúdos aqui discutidos são particulares a cada ambiente possuindo características próprias em relação aos seus objetivos institucionais e quanto ao seu público-alvo. As técnicas de apresentação e representação da informação nesses ambientes proporcionam uma forma eficaz de favorecer o sujeito que interage com a informação na aquisição, uso, recuperação e disseminação da informação para a educação e criação de conhecimento, sendo parte do paradigma emergente atual e capaz de enfrentar as dificuldades inerentes ao processo infocomunicacional.

\section{CONSIDERAÇÕES FINAIS}

Investigar qualquer disciplina na contemporaneidade é um problema complexo por todas as variáveis envolvidas, tanto em sua criação, quanto em sua configuração como área do conhecimento. Notamos que as disciplinas que lidam com a informação estão em constante aprimoramento, com a finalidade de desenvolver novas formas de representação e apresentação dos conteúdos.

Por tratarmos de uma pesquisa que visa oferecer subsídios para solucionar problemas envolvendo a forma de apresentação de informação ao público, percebemos que nossos esforços podem resultar em soluções importantes ao trabalhar as áreas do Design da Informação e Ciência da Informação, de forma interdisciplinar e conjunta: essa união pode significar mais um passo importante que a área almeja alcançar, em busca de preencher uma lacuna conceitual existente.

Por meio da pesquisa desenvolvida, foi possível apresentar o conhecimento teórico da disciplina do Design da Informação, possibilitando alicerçar uma base sólida de conteúdo, visando principalmente operar um conceito novo para a área de Ciência da Informação. Este objetivo foi alcançado devido à análise criteriosa de todo o material bibliográfico pesquisado. A criação de uma revisão de literatura baseada na característica interdisciplinar das áreas envolvidas possibilitou explorar e descrever os principais aspectos que as circundam. A temática analisada propiciou conhecimentos e as condições necessárias para se atuar proativamente na apresentação visual em ambientes informacionais de caráter físico ou digital, ao se considerar as potencialidades que estes oferecem tanto aos profissionais, quanto aos usuários que interagem com a informação.

Com a atividade do design da informação, adequamos a mensagem de forma a favorecer a identidade presente em comunidades culturais, agregando valor sintático e semântico às representações do conhecimento disponíveis em um suporte físico ou digital. 
Compreendemos que o Design da Informação pode ser entendido como um novo campo para a Ciência da Informação que busca sistematizar o oferecimento de informações, tornando-as mais facilmente apreendidas, entendidas, e colocadas em prática. Esta prática profissional irá sistematicamente ampliar-se ao aplicar os conhecimentos advindos de outras áreas, como na interação homem-computador, nos estudos de fatores humanos, nas teorias da comunicação e na Ciência da Informação.

Nesse contexto, identificamos e discutimos perspectivas interdisciplinares e exemplificamos alguns ambientes digitais que pautam a apresentação e comunicação da informação visual por meio do design gráfico e principalmente da atividade de design da informação. Os exemplos contribuíram para analisar projetos importantes que aplicam práticas do Design da Informação nos ambientes digitais de modo adequado, favorecendo o sujeito informacional no processo de aquisição da informação. Os ambientes digitais mencionados estão inseridos no âmbito do paradigma pós-custodial, científico e tecnológico e da Experiência do Usuário em ambientes com base na $W e b$, área que se consolida, pois oferece uma relação de troca informacional ampla e capaz de satisfazer aspectos estéticos e funcionais ao facilitar a apreensão de informação pelos sujeitos informacionais.

Entre as perspectivas interdisciplinares para a atualização do perfil do profissional da informação, citamos a abordagem de Blended Librarian, com potencial para a atuação em ambientes de informação híbridos, que estão disponíveis em meio físico e digital. Trabalhar a atualização profissional pode significar um passo importante para criar um modelo adaptável e capaz de solucionar os problemas que envolvem o profissional da informação, as tecnologias e o design, de forma a fortalecer e aprimorar sua atuação.

Com a evolução das áreas no momento atual, concluímos que os esforços interdisciplinares entre ambas, necessitam de incentivo, sobretudo ao levar em consideração que as disciplinas participam de forma generalizadas em nossa vivência, pois estão presentes em diferentes contextos informacionais. Abre-se uma nova fronteira de pesquisa, voltada à eficácia e clareza na comunicação de informação de alta qualidade, tendo o sujeito informacional papel central no processo comunicacional.

Como perspectivas futuras da pesquisa, visamos desenvolver e delimitar a emergência de transdisciplinaridade na atuação dos profissionais da informação em bibliotecas, arquivos, museus e centros de informação híbridos, utilizando os conhecimentos do Design da Informação como princípio orientador da disseminação de informação na contemporaneidade.

Dessa forma, buscamos aliar teoria e prática ao realizar a aplicação dos conceitos apontados junto aos profissionais da área de Ciência da Informação, sendo esta uma limitação do presente artigo. Por meio da análise experimental social será possível verificar na prática os principais aspectos que permeiam a atividade acadêmica, científica e profissional de tais indivíduos e os resultados atingidos ao aplicar os conhecimentos discutidos aqui.

Tratamos de uma perspectiva atual que terá como desafio a aceitação e incorporação dos fundamentos, princípios, teorias e práticas advindas do Design da Informação. Entre as possíveis áreas com potencial de aplicação, podemos citar a sinalização em ambientes informacionais, promover ações que ampliem a acessibilidade e usabilidade, atentar para aspectos de legibilidade e leiturabilidade em ambientes físicos ou digitais, aperfeiçoamento de ferramentas de interfaces de recuperação da informação, aprimorando e garantindo ao sujeito informacional experiências realmente proveitosas.

\section{AGRADECIMENTOS}

Agradecimentos especiais à Fundação de Amparo à Pesquisa do Estado de São Paulo (FAPESP), processo número 2016/23677-4, pelo apoio financeiro ao projeto de pesquisa. 


\section{REFERÊNCIAS}

BELL, S.; SHANK, J. D. The blended librarian: a blueprint for redefining the teaching and learning role of academic librarians. College \& Research Libraries News, v. 65, n. 7, p. 372-375, Jul./Aug. 2004.

Disponível em: <http://crln.acrl.org/content/65/7/372.full.pdf>. Acesso em: 20 Jan. 2018.

BELL, S.; SHANK, J. D. Academic Librarianship by Design: A Blended Librarian's Guide to the Tools and Techniques. Chicago: ALA, 2007.

BERTIN, J. Semiology of Graphics. Madison: University of Wisconsin Press, 1983.

BONSIEPE, G. Design, do material ao digital. Florianópolis: FIESC/IEL, 1997.

CARROLL, J. M.; Rosson, M. B. Usability Engineering: Scenario-Based Development of Human Computer Interaction. Morgan Kaufmann: San Francisco, 2002.

COOPER HEWITT MUSEUM. Instructional Bandage. 2018. Disponível em: <http://www.cooperhewitt.org/2013/11/23/an-instructional-bandage>. Acesso em: 10 jul. 2018.

DONDIS, D. A. Sintaxe da linguagem visual. São Paulo: Martins Fontes, 1997.

FRASCARA. J. ¿Qué es el diseño de información?. Buenos Aires: Ediciones Infinito, 2011.

GARRETT, J. J. The Elements of User Experience: User Centered Design for the Web. Indianapolis: New Riders, 2002.

HOLLIS, R. Design gráfico: uma história concisa. Tradução Carlos Daudt. São Paulo: Martins Fontes, 2000.

HORN, R. Information Design: Emergence of a New Profession. In: R. Jacobson (Org.). Information Design. Cambridge, Massachusetts: The MIT Press, 1999. p. 15-33.

JACOBSON, R. Information Design. Cambridge, Massachusetts: The MIT Press, 1999.

JORENTE, Maria José Vicentini. Tecnologias, mídias, criação e hipertextualidade na transformação da informação em conhecimento interativo. 2009. 257f. Tese (Doutorado) - Faculdade de Filosofia e Ciências, Universidade Estadual Paulista, Marília, 2009.

JORENTE, M. J. V. Archives Information Publishing New Design in Post-Custodial Regime: the National Archives Experience Digital Vaults. Information Services and Use, v. 31, n. 3-4, p. 147-155, 2011. Disponível em: < http://iospress.metapress.com/content/nj53137851h126r4/>. Acesso em: 10 jul. 2018.

JORENTE, M. J. V. (Org.) Tecnologia e Design da Informação: interdisciplinaridades e novas perspectivas para a Ciência da Informação. Bauru, São Paulo: Canal 6, 2015.

KATZ, J. Designing Information: Human Factors and Common Sense in Information Design. New York: Wiley, 2012.

LIBRARY OF CONGRESS. 2018. Disponível em: < https://www.loc.gov/>. Acesso em: 20 jun. 2018.

MACEDO, F. L. O. Arquitetura da informação: aspectos epistemológicos, científicos e práticos. 2005. 190 f. Dissertação (Mestrado em Ciência da Informação) - Universidade de Brasília, Brasília, DF, 2005.

MEGGS, P. B.; PURVIS, A. W. História do design gráfico. São Paulo: Cosac Naify, 2009.

MEIRELLES, I. Design for Information: An Introduction to the Histories, Theories, and Best Practices Behind Effective Information Visualizations. Beverly, MA: Rockport Publishers, 2013.

ORNA, E.; STEVENS, G. Information design and information science: a new alliance? Journal of information science, n. 17, v. 4, p. 197-208, 1991. 
ORNA, E. Collaboration between library and information science and information design disciplines. On what? Why? Potential benefits? Information Research, n. 12, v. 4, 2007. Disponível em: $<$ http://InformationR.net/ir/12-4/colis/colis02.html>. Acesso em: 12 fev. 2018.

PETTERSSON, R. Information design: an introduction. Amsterdam: John Benjamins Publishing Co, 2002.

PONTIS, S. 20 Information Design Milestones. Mapping Complex Information. 2012. Disponível em: <http://sheilapontis.wordpress.com/2012/01/16/20-information-design-milestones/>. Acesso em: 15 jul. 2018.

RUBIN, T. User Interface Design for Computer Systems. New York: John Riley \& sons, 1988.

SILVA, A. M. da; Ribeiro, F. Paradigmas, serviços e mediações em Ciência da Informação. Recife: Nectar, 2011.

SILVA, A. M. O Método Quadripolar e a Pesquisa em Ciência da Informação. Prisma.com, n. 26, p. 27-44, 2014. Disponível em: < http://revistas.ua.pt/index.php/prismacom/article/view/3097>. Acesso em: 15 dez. 2017.

SOCIEDADE BRASILEIRA DE DESIGN DA INFORMAÇÃO (SBDI). Brasil, 2017. Disponível em: <http://www.sbdi.org.br>. Acesso em: 12 jun. 2018.

TATE MUSEUM. 2018. Disponível em: < http://www.tate.org.uk/>. Acesso em 10 dez. 2017.

TUFTE, E. R. The Visual Display of Quantitative Information. Cheshire, Conn.:Graphics Press, 1983.

TRAMULLAS SAZ, J. Planteamiento y componentes de la disciplina "Information Design". Cuadernos de documentación multimedia, 10, 2000. Disponível em: <

http://pendientedemigracion.ucm.es/info/multidoc/multidoc/revista/num10/paginas/pdfs/jtramulla s.pdf>. Acesso em: 18 jul. 2018.

WARE, C. Information Visualization: Perception for Design. Morgan Kaufman Publishers Inc., 2000.

WILBUR, P.; BURKE, M. Information Graphics: Innovative Solutions in Contemporary Design. London: Thames \& Hudson, 1998.

Editores do artigo: Enrique Muriel-Torrado, Edgar Bisset Alvarez, Camila Barros. 